\title{
COMMENTARY
}

\section{The Challenge of Implementing the Sustainable Development Goals in Africa: The Way Forward}

\author{
Rotimi Jaiyesimi
}

Associate Medical Director for Patient Safety and Consultant Obstetrician and Gynaecologist, Basildon University Teaching Hospital, England; Visiting Professor, Faculty of Applied Sciences, University of Sunderland, England and Visiting Professor, Faculty of Law, University of Ibadan, Nigeria

*For Correspondence: Email: jaiyesimi@obs-gyn.org; Phone: +447415900457

Nations of the world met in September 2015 at the UN in New York and adopted the Sustainable Development Goals ${ }^{1}$, the successor framework to the Millennium Development Goals (MDGs) which were agreed by governments in 2000 and which came to an end in 2015. The MDGs concentrated largely, though not exclusively, on social outcomes while key development priorities, such as infrastructure and energy, were absent from the list. The SDGs (Table 1) reflect the challenges we face in development, emphasising the underlying drivers of sustainable development and not just measurable outcomes. The SDGs have adopted an all-inclusive approach, taking on board challenges faced by all nations and promoting the cooperation between the private and public sector in the execution of the goals.

\section{Opportunities and challenges}

The Sustainable Development Goals (SDGs) provides opportunities as well as challenges for developing countries, as the cost of its implementation will be high though it can bring long-term benefits. Nations are different and have their peculiarities and different perspectives. It is important that each nation should translate each relevant SDG into National Plans of Action. This must be borne in mind when creating plans and policies for Africa. Four major challenges that need to be addressed for achieving the SDGs in Africa are financial, maintaining peace, measuring progress and accountability ${ }^{2}$.

\section{Implementation}

The Sustainable Development Goals are made up of 17 goals and 169 targets. The spirit and agenda of the SDGs are commendable as they combine efforts to eradicate poverty and increase the development of poor countries. The SDGs is expected to take a more inclusive and diverse approach by mobilizing actors in both developed and developing countries ${ }^{3}$.

However, focus should be on integration among the substantive goals and targets. Vital as this may be, there is the need for similar attention to be devoted to obtaining a systems view and integrated approach to the means of implementation, dispersed in an imbalanced way through all the goals and specifically in Goal $17^{1}$.

Across the goals, 42 targets focus on means of implementation, albeit somewhat unevenly, while the final goal, Goal 17 , is entirely devoted to means of implementation. However, these implementation targets are largely silent about interlinkages and interdependencies among goals, regardless of their ambition to be "universal, indivisible, and interlinked". This leaves open the possibility of perverse outcomes and unrealised synergies ${ }^{1}$. Examples include situations where achieving human development in the short term may undermine the capacity of the global life support system ${ }^{4}$ to support advances in human well-being in the long term; or, indeed, where environmental interventions undermine the rights and well-being of certain social groups 5 . For example, promoting increased consumption to alleviate poverty may lead to the failure of other goals, such as the sustainable management of water. Uncoordinated action may create internal conflicts, such as subsidies for both renewable and non-renewable fuel sources, or missed synergies, for example, where appropriately targeted investment in renewable energy reduces emissions, but it could also reduce pollution, improve human health, and increase equality. 
Table 1: The 17 Sustainable Development Goals

\begin{tabular}{llrl}
\hline SDG & & SDG & \\
\hline $\mathbf{1}$ & No poverty & $\mathbf{9}$ & Industry, innovation, and infrastructure \\
$\mathbf{2}$ & Zero hunger & $\mathbf{1 0}$ & Reduce inequality \\
$\mathbf{3}$ & Good health and well-being & $\mathbf{1 1}$ & Sustainable cities and communities \\
$\mathbf{4}$ & Quality education & $\mathbf{1 2}$ & Responsible consumption and production \\
$\mathbf{5}$ & Gender equality & $\mathbf{1 3}$ & Climate action \\
$\mathbf{6}$ & Clean water and sanitation & $\mathbf{1 4}$ & Life under water \\
$\mathbf{7}$ & Affordable and clean energy & $\mathbf{1 5}$ & Life on land; \\
$\mathbf{8}$ & Decent work and economic growth & $\mathbf{1 6}$ & Peace, justice, and strong institutions \\
$\mathbf{1 7}$ & Partnership for the goals & & \\
\hline
\end{tabular}

Spreading implementation targets throughout the goals encourages systemic implementation. To be successful there must be greater attention on interlinkages in three areas: 1) Across sectors (e.g. Finance, agriculture, energy, and transport); 2) across societal actors (local authorities, government agencies, private sector, and civil society); and 3) between and among low, medium and high income countries.

As a framework, the SDGs extend the MDGs in many ways, but particularly by seeking to profoundly link the social, economic, and environmental aspects of goals. This in turn implies linking across time ensuring that the shortterm achievement of improved human well-being does not occur at the cost of undermining wellbeing in the long term by damaging the underpinning social and environmental capital on which our global life support system depends ${ }^{1}$.

The UN's categorisation of means of implementation of the SDGs includes finance, technology, capacity building, trade, policy coherence, partnerships, and, finally, data, monitoring and accountability. This is where the importance of the application of Sustainability Science comes in. Sustainability science probes interactions between global, social, and human systems, the complex mechanisms that lead to degradation of these systems, and concomitant risks to human well-being. Serious sustainable development problems dominate policy discussion in many countries, but with little actual results in terms of complex global environmental problems like climate change. Where progress in social indicators is made, it often comes at an environmental cost. Inter-linkages across different goals will be a challenging area, and the inherent trade-offs and complexity of such an effort requires that related policies be informed by a science of sustainability ${ }^{1}$.

The UN's categorisation of means of implementation of the SDGs indicators will require an unprecedented amount of data to be produced and analysed. Without quantified targets and monitoring, it is impossible to determine whether sufficient progress is being made. This will be the problem for most African countries. The SDGs place greater demands on the scientific community than did the Millennium Development Goals (MDGs), which they replace ${ }^{6}$. Addressing climate change, renewable energy, food, health and water provision requires coordinated global monitoring and modelling of many factors - social, economic and environmental. African nations may struggle to provide coordinated monitoring due to the dearth of personnel skilled to undertake this task. There is no doubt that the implementation will pose a significant challenge for national statistical systems. It is for this reason that collaboration with international and scientific agencies will be required to help devise metrics, establish monitoring mechanisms, evaluate progress and standardise and verify data. African countries lack the infrastructure to undertake earth observation, ground-based monitoring and information-processing capabilities required to give better global coverage, to allow direct comparisons of data by using similar instruments, and to store, analyse and share data. This can be overcome by collaboration between developed and developing countries ${ }^{7}$. African nations can be ingenious by using smartphones for data gathering such as point source information such as immunisation $^{8}$.

The successful implementation of the SDGs depends on standardised and accurate data. 


\section{Rotimi Jaiyesimi}

Scientists and governments need to design monitoring and evaluation mechanisms into policy-making at all levels and to verify data ${ }^{9}$. Drawing on a global sustainability science and practice perspective, there are seven recommendations to improve these interlinkages at both global and national levels, in relation to the UN's categories of means of implementation: finance, technology, capacity building, trade, policy coherence, partnerships, and, finally, data, monitoring and accountability. In practice, much implementation will occur at national and local levels and should take into consideration the following:

\section{Policy}

During the period of the MDGs, individual UN agencies took charge of individual targets and implemented them with limited regard for other targets. The lack of clear guidance on policy changes or how the goals ought to be achieved were some of the often reported challenges to the implementation of $\mathrm{MDGs}^{9,10}$. This lack of guidance resulted in varying perspectives, neglect of targets that concerned the environment, interpretations and avenue for cynicism, especially in low-resource nations. To avoid this, there is a strong need for policy and institutional coherence. The strong global and national oversight of integrated development plans brings about a strong link between sectors and actors ${ }^{1}$.

A significant policy innovation with the SDGs is the creation of the UN's High-Level Political Forum (HLPF), which is scheduled to meet annually at the ministerial level, and every fourth year at the heads of state level. The HLPF is tasked with ensuring the integration of the three dimensions of sustainable development in a holistic and cross-sectoral manner at all levels. It is meant to have higher authority than similar previous institutions at the $\mathrm{UN}$, to coordinate, secure interlinkages, mobilize resources for implementation, and monitor progress ${ }^{11}$.

\section{Finance}

Achieving success in a programme as huge as the SDGs requires a massive amount of financial investments. The rough calculations have put the cost of providing social safety nets to eradicate
Implementation of the SDGs in Africa

extreme poverty globally at about $\$ 66$ billion a year, while annual investments to improve infrastructure (water, agriculture, transport, and power) could be up to a total of $\$ 7$ trillion globally $^{12}$. At the international level, most developed countries have not met the target of allocating $0.7 \%$ of Gross National Income (GNI) to international aid in the last 40 years. It will help provide much-needed funds required to implement the goals if these countries could meet their international aid targets.

The dependence of low-resource nations on donor agencies has not produced the desired results for various reasons. Nations or Foundations alone will not be able to deliver on the ambitious vision for global sustainable growth and inclusive development that is at the core of the SDGs. Many government aid budgets are not expanding and the private sector will have to take more of the financing and service delivery gaps to achieve the goals. The private sector can and should become a key partner in this process while large scale government funding remains essential. There should be different types of private sector engagement, finding the appropriate private sector source of finance for each goal.

Businesses from high income countries still mostly avoid investment in building the business capacity of lower income countries, even where these are politically stable. Incentivising such long-term private investments from high income countries towards lower income countries requires pools of "patient capital" - capital investment that measures returns not on a quarterly or annual basis, but rather over decades and more, mandated for lower income nations.

It is important that there is a link across sectors and countries through incentives for the long-term investment in early stage market development in lower income countries, particularly for products and services that support sustainable development. If the SDGs are to succeed, they must promote an inclusive approach to growth, and mobilize innovative sources of financing while phasing out investment in unsustainable activities in all countries ${ }^{1}$.

\section{Financial prudence and accountability}

There must be accountability for inputs into SDGs 


\section{Rotimi Jaiyesimi}

at all levels. Donor support to leverage private investment - and private finance generally - needs to be compliant with development effectiveness principles, and there must be robust environmental and social safeguards ${ }^{13}$. There is need for transparency about how private finance is utilised and political leaders and public servants need to show integrity in the manner funds from any source are utilised.

\section{Capacity building}

Capacity building is important to the success of the SDGs and its goal is to provide the long-term foundation for transformation. While this is often location specific, at a fundamental level, it will require all sectors in all countries to acquire new skillsets and toolkits for sustainability. It requires training and education in systems approaches to solutions, transdisciplinary initiatives, and codesign. What is required is a new generation and category of sustainability professionals who can broker between global, national, and local issues, between research and use, and between biophysical and social aspects of sustainability; notably, this need is as acute in higher as in lower income countries ${ }^{14}$. This may be difficult for most African countries due to the dearth of skilled workforce. However, there is no better time than now for these countries to call upon the skills and knowledge of their citizens in the diaspora.

\section{Technology and data to drive improvement}

The availability of quality data allows for an effective assessment of the outcome of any intervention. The gathering of data on a massive scale and the analysis of the data requires investment in technology. This allows for determination of trends and themes and to allow for adjustments to be made when departing from agreed objectives. The non-availability and reliability of data were the most often reported challenges with regards to the implementation of the MDGs and subsequently in the interpretation of progress reports ${ }^{15,16,17}$.

Key Performance Indicators (KPI) will be required to measure the progress being made in attaining the goals. To date, these have not yet been defined. An identifiable problem with the
Implementation of the SDGs in Africa

SDGs is that a number of the targets proposed are not quantifiable. If one were to propose two KPIs per target, this will equate to 338 indicators. These KPIs need to meet the SMART objectives of being Specific, Measurable, Achievable, Realistic and Time-related.

The knowledge of complex systems has enabled the distillation of essential variables within the 230 indicators which capture major dimensions of change in various systems. These have paved the way to identifying a set of "essential sustainable development variables" that define a core minimum set of social, environmental and economic measurements for monitoring while at the same time supporting a more integrated set of indicators for tracking and communicating progress. Such an integrated suite of indicators that link across sectors could be adapted and used by developed and low-resource nations, UN agencies and the private sector multiple actors and could be aggregated across scales. The task ahead of monitoring or evaluating the indicators for measuring progress cannot be underestimated. It will require the availability of the data, the quality of the data and the capacity to measure them. A quality improvement methodology which adopts a stepwise improvement in attaining the goals over the coming years rather than a quantum leap and unsustainable progress is recommended. This will measure the pace of progress rather than difficult to attain specific KPIs or specific targets. It also allows for improvement changes to be made where required.

We live in times of wars and terrorism and a threat to national and international peace and stability by non-state actors is emerging as a major factor for both developed and developing countries. At the heart of the SDGs are people are at the heart of what we do. These wars and acts of terrorism result in internally displaced people and refugees and do not augur well for development. Maintaining peace becomes a critical success factor.

Sustaining the momentum and advancing the gains made under the MDGs will therefore require new approaches which embrace all three dimensions of sustainability - environmental, economic and social. In this context, African 


\section{Rotimi Jaiyesimi}

countries will need to adopt more inclusive growth strategies that create decent jobs for broad sections of society, promote equity and meet the development needs of present generations without compromising the ability of future generations to meet their own needs. The implementation of these will require commitment from governments and this will be achieved through adequate funding, financial prudence and ensuring value for money.

\section{Conclusion}

An in-depth review of the other determinants of success of the SDGs is beyond the scope of this commentary but suffice it to say that the SDG agenda needs not only to pay attention to implementing the substantive goals (SDGs 1-16) in integrated ways, but also to ensuring that the means of implementation in Goal 17 and the other goals are themselves an integrated undertaking ${ }^{18}$. The defining challenge of our era is to accelerate development that is economically sound, socially inclusive and environmentally sustainable. The Sustainable Development Goals embody nothing less and represent the best possible opportunity of all the complexities of economic development that we face today.

The looming challenges in Africa are wide and deep and will require innovative responses that are embedded in partnerships and rooted in our shared values of justice, fairness, equity and solidarity. The time is now to ensure that Africa is not left behind in achieving the SDGs and the beneficiaries of this will be Africans and the people of the world at large. The measure of our success in implementing the sustainable development goals in Africa will be the attainment of the components of the 17 goals by 2030 . It can be done, provided the key factors important for successful implementation of SDGs, high level of political support, ownership by the countries, institutional and human capacity development, inclusive of development process, mutual accountability, and policy reform are established and sustained. The success of the sustainable development goals in Africa will hinge on a credible means of implementation.
Implementation of the SDGs in Africa

\section{Conflict of Interest: None}

\section{References}

1. Stafford-Smith, M., Griggs, D., Gaffney, O. et al. Sustain Sci (2016). doi:10.1007/s11625-0160383-3.

2. Kumar S, Kumar N, Vivekadhish S. Millennium Development Goals (MDGs) to Sustainable Development Goals (SDGs): Addressing Unfinished Agenda and Strengthening Sustainable Development and Partnership. Indian Journal of Community Medicine: Official Publication of Indian Association of Preventive \& Social Medicine. 2016;41(1):1-4.doi:10. 4103/ 0970-0218.170955.

3. Sustainability Science, Call for paper for sustainability science and implementing the sustainable development goals, March 2016, Volume 11, Issue 2, pp 177-178.

4. Griggs D, Stafford-Smith M, Gaffney O, Rockstrom J, Ohman MC, Shyamsundar P, Steffen W, Glaser G, Kanie N, Noble I (2013) Policy: sustainable development goals for people and planet. Nature 495(7441):305-307.

5. Leach M (ed) (2015) Gender equality and sustainable development. Routledge, Abingdon.

6. International Council for Science, International Social Science Council. Review of Targets for the Sustainable Development Goals: The Science Perspective, ICSU, 2015.

7. Saint Petersburg Development Outlook: Annex to the G20 Leaders' Declaration (G20, 2013).

8. Lu Y, Nakicenovic N, Visbeck M, Stevance, A.(2015) Policy: Five priorities for the UN Sustainable Development Goals, Nature, Volume 520, Issue 7548.http://www.nature.com.gate3.library.lse.ac. uk/news/policy-five-priorities-for-the-un sustainable-development-goals-1.17352 (accessed 26 August 2016).

9. Fukuda-Parr S. Millennium development goal 8: Indicators for international human rights obligations? Human Rights Quarterly. 2006;28:9 66-997. doi:10.1353/hrq.2006.0046.

10. Gil-Gonzalez D., Ruiz-Cantero M. T., Alvarez-Dardet C. How political epidemiology research can address why the millennium development goals have not been achieved: Developing a research agenda. Journal of Epidemiology and Community Health. 2009;63:278-280. doi:10.1136/jech.2008 .082347 .

11. Bernstein S, Gupta J, Andresen S, Haas PM, Kanie N, Kok M, Levy MA, Stevens C (2014) Coherent Governance, the UN and the SDGs. POST2015/ UNU-IAS policy brief \#4. United Nations University Institute for the Advanced Study of Sustainability, Tokyo.

12. Report of the Intergovernmental Committee of Experts 


\section{Rotimi Jaiyesimi}

on Sustainable Development Financing 2014. Accessed 27 July 2016 from https://sustainabled evelopmentunorg/content/documents/4588FINA L\%20REPORT\%20 ICE SDF.pdf.

13. Global development professionals network, Develop ment 2030. Seven ideas on how to finance the SDGs.https://www.theguardian.com/global-deve lopment-professionals-network/2016/jan/26/ eight-ideas-how-fund-sdgs-sustainable-develop ment - Accessed 27 July 2016.

14. Leach M, Rockstrom J, Raskin P, Scoones I, Stirling AC, Smith A, Thompson J, Millstone E, Ely A, Arond E et al (2012) Transforming innovation for sustainability. Ecol Soc 17(2):11. doi:10.5751/es04933-170211.

15. Dar O. A., Khan M. S. Millennium development goals and the water target: Details, definitions and
Implementation of the SDGs in Africa

debate. Tropical Medicine \& International Health. 2011;16:540-544. doi:10.1111/j.13653156.2011.02736.x.

16. Easterly W. How the millennium development goals are unfair to Africa. [Article] World Development. 2009;37(1):26-35.

doi:10.1016/j.worlddev.2008.02.009.

17. Sachs J. D. From millennium development goals to sustainable development goals. Lancet. 2012;379:2206-2211. doi:10.1016/S0140-6736 (12)60685-0.

18. Fehling $\mathrm{M}$, Nelson $\mathrm{BD}$, and Venkatapuram, S. Limitations of the Millennium Development Goals: a literature review. Glob Public Health. 2013 Dec; 8(10): 1109-1122. Published online 2013 Nov 25. doi: 10.1080/17441692 .2013. 845676). 